\title{
The chemical case for Mercury mantle stripping
}

\author{
George Helffrich $^{1 *}$ (D), Ramon Brasser ${ }^{1}$ and Anat Shahar ${ }^{2}$
}

\begin{abstract}
Mercury, the Solar System's innermost planet, has an unusually massive core prompting speculation that the planet lost silicate after it formed. Using the unusually high sulfur and low iron composition of its surface and space geodetic constraints on its core composition, we show Mercury's chemistry to be compatible with formation in a larger planet at minimum 1.4-2.5 times Mercury's present mass and possibly 2-4 times its mass by similarity with other rocky Solar System bodies. To do this, we apply an experimentally determined metal-silicate partitioning model for sulfur to Mercury's silicate. The model is validated by applying it to Vesta, which, when evaluated at the conditions of Vestan self-differentiation, yields sulfur contents in its silicate in the range of HED meteorites. Mercury could have lost a substantial fraction of its rocky material through impacts or by being itself a remnant impactor. Independent of any stripping, because a significant amount of silicon resides in Mercury's core, silicate meteoritic debris from Mercury would likely be characterized by ${ }^{30} \mathrm{Si}$ isotopic enrichment $>+0.10 \%$ relative to parent sources that could aid identification of a new meteorite class.
\end{abstract}

Keywords: Mercury, Vesta, Sulfur, Silicon, N-body simulation, Meteorites, Stable isotopes

\section{Introduction}

Mercury is essentially a metal core draped with a thin silicate mantle. Detailed models of its interior structure (Rivoldini et al. 2009; Rivoldini and Van Hoolst 2013; Hauck II et al. 2013; Dumberry and Rivoldini 2015) indicate core radii of $2000-2060 \mathrm{~km}$ and a core proportionately $58-70 \%$ of the planetary mass $\left(M_{\succ}, 3.302 \times 10^{23}\right.$ $\mathrm{kg}$ (Rivoldini et al. 2009)). By comparison, Earth's core is $32 \%$ of the planetary mass (Stacey 1992), Venus 24-32\% (Fegley 2014), Mars' and Vesta's cores are 21 and 18\%, respectively, of the planetary mass (Rivoldini et al. 2011; Russell et al. 2012), and the fractional mass of metallic elements in chondritic meteorites is $\sim 30 \%$ (McDonough and Sun 1995). These facts suggest that Mercury might have lost part of its original mantle at some point in the Solar System's history through impacts with other bodies, stripping it of its silicate and leaving metal (Benz et al. 1988; Benz et al. 2007; Asphaug and Reufer 2014). Moreover, spectroscopic observations of Mercury's surface by

*Correspondence: george@elsi.jp

${ }^{1}$ Earth-Life Science Institute, Tokyo Institute of Technology, 2-12-1 Ookayama, Meguro-ku, Tokyo, 152-8550 Japan

Full list of author information is available at the end of the article the MESSENGER mission (Nittler et al. 2011; Zolotov et al. 2013; Weider et al. 2014) indicate high concentrations of sulfur (1-6 wt\%) and low concentrations of $\mathrm{FeO}$ $(<1.9 \mathrm{wt} \%)$. From a planetological perspective, this rather weird chemical imprint compared to either the Earth or to $\mathrm{CI}$ carbonaceous chondrites (Earth: $\sim 0.03 \mathrm{wt} \% \mathrm{~S}$, $\sim 8 \mathrm{wt} \% \mathrm{FeO}$; CI $5.4 \mathrm{wt} \% \mathrm{~S}, 15.1 \mathrm{wt} \% \mathrm{FeO}$ (McDonough and Sun 1995)) suggests that it may have arisen under unusual conditions. Chabot et al. (2014) showed that it is difficult to reconcile the observed surface $\mathrm{FeO}$ content with equilibrium between silicate and metal at pressures up to that of Mercury's present core-mantle boundary (CMB). Other studies showed plausible ways to build Mercury from chondritic and non-chondritic precursors (Ebel et al. 2018; Cartier and Wood 2019). Here we approach the problem via accretion modeling. Accretion models for the Earth and other rocky planets use experimentally determined metal/silicate partition coefficients to constrain the physical conditions during formation ( $\mathrm{Li}$ and Agee 1996; Wood et al. 2006; Rubie et al. 2015). These models assume that the composition of the metal and silicate is set by equilibrium partitioning of elements at the rheologically solid base of liquid silicate when a planet's surface is partly or completely molten due to impact 
heating (Kaula 1979; Rubie et al. 2015). Under these conditions, the liquid metal separates from the liquid silicate and accumulates in the core of the planet, ceasing to be in chemical equilibrium with silicate. Consequently, we use a model for sulfur, silicon, oxygen, carbon, and iron partitioning between metal and silicate to evaluate whether there are feasible conditions for Mercury that simultaneously satisfy the composition of the silicate mantle while yielding core compositions that satisfy space geodetic constraints. Our objective is to show that Mercury's surface chemistry is compatible with the formation in an originally larger body from which the mass was lost by impact processing.

\section{Methods}

\section{Sulfur partitioning model}

We use Boujibar et al.'s (2014) S partitioning model to determine the pressure- $(P)$ and temperature- $(T)$ dependent joint $\mathrm{S}$ and $\mathrm{FeO}$ content of the silicate. This reads,

$$
\begin{aligned}
\log _{10} D_{\mathrm{S}}^{\mathrm{met} / \mathrm{sil}} & =\log _{10}\left[X_{\mathrm{S}}^{\mathrm{met}} / X_{\mathrm{S}}^{\mathrm{sil}}\right]= \\
& \log _{10} W_{\mathrm{FeO}}^{\mathrm{sil}}-\log _{10} C_{\mathrm{S}}+b / T+c P / T \\
& +d \log _{10}\left(1-X_{\mathrm{Si}}^{\mathrm{met}}\right)+e \log _{10}{ }^{2}\left(1-X_{\mathrm{Si}}^{\mathrm{met}}\right)+f \log _{10}{ }^{3}\left(1-X_{\mathrm{Si}}^{\mathrm{met}}\right) \\
& +g \log _{10}\left(1-X_{\mathrm{C}}^{\mathrm{met}}\right)+h \log _{10}\left(1-X_{\mathrm{Fe}}^{\mathrm{met}}\right)+i \log _{10}\left(1-X_{\mathrm{Ni}}^{\mathrm{met}}\right) \\
& +j \log _{10}\left(1-X_{\mathrm{O}}^{\mathrm{met}}\right)+k .
\end{aligned}
$$

$b-k$ are experimentally determined model coefficients, listed in Table 1 . The metal concentrations $X_{i}^{\text {met }}$ and $X_{S}{ }^{\text {sil }}$ are weight fractions, whereas silicate $\mathrm{FeO}$ concentration $W_{\mathrm{FeO}}^{\text {sil }}$ is weight percent. $C_{\mathrm{S}}$ is the sulfur carrying capacity, given by

$$
\begin{gathered}
\log _{10} C_{\mathrm{S}}=-5.704+3.15 \times X_{\mathrm{FeO}}+2.65 \times X_{\mathrm{CaO}}+0.12 \times X_{\mathrm{MgO}}+ \\
0.77 \times X_{\mathrm{TiO}_{2}}+0.75 \times\left(X_{\mathrm{Na}_{2} \mathrm{O}}+X_{\mathrm{K}_{2} \mathrm{O}}\right) .
\end{gathered}
$$

Here, by contrast with (1), the oxide concentrations $X_{i}$ are mole fractions in the silicate.

In order to evaluate these expressions, we need the composition of core metal, in particular its concentrations of $\mathrm{Fe}, \mathrm{Ni}, \mathrm{O}, \mathrm{C}, \mathrm{Si}$, and $\mathrm{S}$. S is fixed by a family of solutions to the Mercury planetary geodesy data and by estimated mantle compositions which will be reviewed

Table 1 Sulfur solubility model parameters

\begin{tabular}{lllllllllll}
\hline Symbol & $b$ & $c$ & $d$ & $e$ & $f$ & $g$ & $h$ & $i$ & $j$ & $k$ \\
\hline Value & 405 & 136 & 32 & 181 & 305 & 30.2 & 1.13 & 10.7 & 31.4 & -3.72 \\
\pm & 150 & 25 & 5.5 & 45 & 380 & 6 & 0.14 & 2.5 & 18 & 0.07 \\
Units & K & KGPa-1 & & & & & & & & \\
\hline
\end{tabular}

Used in Eq. (1). Source: Boujibar et al. (2014) below. To obtain the rest, we use thermodynamic constraints on metal/silicate partitioning of $\mathrm{Si}, \mathrm{O}$, and $\mathrm{C}$ from various sources, assuming a single-stage core formation model. To obtain the oxygen content of the metal, we use Frost et al.'s (2010) model for $\mathrm{Fe}+\mathrm{O}$ equilibrium between metal and silicate and the specified silicate mantle content. This gives the activity of an "FeO" component in the metal from which the $\mathrm{O}$ and Fe concentrations may be obtained by

$$
X_{\mathrm{Fe}}^{\mathrm{met}} \times X_{\mathrm{O}}^{\mathrm{met}}=\frac{a_{\mathrm{FeO}}}{\gamma_{\mathrm{Fe}}^{\mathrm{met}} \times \gamma_{\mathrm{O}}^{\mathrm{met}}} .
$$

$\mathrm{Ni}$ is obtained by assuming a chondritic mass ratio $X_{\mathrm{Ni}} / X_{\mathrm{Fe}}=0.06$ (McDonough and Sun 1995). C is obtained by assuming saturation in the metal. We justify this choice based on the quite large $C$ concentrations implied with Marcyr's high $\mathrm{S}$ abundances using the chondritic $\mathrm{C} / \mathrm{S}$ ratio (0.648) (McDonough and Sun 1995), because models of Mercury formation invoke an early graphite crust (Kaaden and McCubbin 2016; Cartier and Wood 2019), and because graphite appears to be present on Mercury's surface (Peplowski et al. 2015). We use Wood's (1993) parameterization for $\mathrm{C}$ saturation in metal, and use the pressure of the depth of the base of the magma ocean to set the $P$ and $T$ conditions; see Additional file 1: Figure S1 for a plot of $\mathrm{C}$ saturation vs pressure. $\mathrm{Si}$ is obtained from Hirose et al.'s (2017) model for joint $\mathrm{Si}$ and $\mathrm{O}$ metal/silicate partitioning. The metal activity coefficients $\gamma_{i}$ are evaluated using the $\epsilon$ formalism (Ma 2001) with interaction parameters given in Table 2. An iterative method is used to solve consistently for $\mathrm{Si}$ concentration and metal activity coefficients given the $\mathrm{Si}$ and $\mathrm{O} K_{\mathrm{D}} \mathrm{s}$ and $\mathrm{C}$ concentration. Table 3 gives metal Si content at $2 \mathrm{wt} \% \mathrm{~S}$.

Peridotite solidus and liquidus temperatures are from

\begin{tabular}{|c|c|c|c|c|c|c|}
\hline$\epsilon_{j}^{i}=\epsilon_{i}^{j}$ & $\begin{array}{l}i \rightarrow \\
j \downarrow\end{array}$ & $\mathrm{Ni}$ & $\mathrm{Si}$ & C & $\mathrm{O}$ & $S$ \\
\hline$S$ & & -0.05 & 9.16 & 6.12 & 0 & -5.66 \\
\hline $\mathrm{O}$ & & 1.4 & 7.73 & -20.08 & -9.16 & \\
\hline C & & 2.31 & 9.70 & 12.83 & & \\
\hline $\mathrm{Si}$ & & 7.5 & 0 & & & \\
\hline $\mathrm{Ni}$ & & 0.12 & & & & \\
\hline
\end{tabular}
Fiquet et al. (2010), whose mean provides the temperature as a function of pressure, eliminating an independent variable. Pressures in the proto-Mercurys are calculated assuming an adiabatic temperature profile with the metal-silicate equilibration pressure fixed at $\frac{1}{2} P_{\mathrm{CMB}}$ and no temperature discontinuity at the CMB. Internal

Table 2 Metal interaction parameters

Sources: O-O, O-Si, Si-Si (Hirose et al. 2017); S-Ni, Si-Ni, S-S, Ni-Ni (Wade et al. 2012); $\mathrm{Ni}-\mathrm{O}$ (Tuff et al. 2011). C-C, C-S, C-O, C-Si, C-Ni MetalAct Website, http://www.earth. ox.ac.uk/ expet/metalact/, accessed 2018/01/04 (Wade and Wood 2005) 
Table 3 Mercury and Vesta mantle compositions

\begin{tabular}{|c|c|c|c|c|}
\hline Oxide & Zolotov $^{a}$ & Chabot $^{b}$ & Nittler $^{C}$ & Vesta $^{d}$ \\
\hline $\mathrm{SiO}_{2}$ & 56.90 & 49.02 & 52.83 & 44.47 \\
\hline $\mathrm{TiO}_{2}$ & 0.89 & 1.07 & 0.22 & 0.12 \\
\hline $\mathrm{Al}_{2} \mathrm{O}_{3}$ & 14.10 & 11.72 & 4.41 & 2.76 \\
\hline $\mathrm{FeO}$ & 3.42 & 0 & 0.03 & 21.02 \\
\hline $\mathrm{MnO}$ & 0.69 & 0 & 0 & 0 \\
\hline $\mathrm{MgO}$ & 17.90 & 29.84 & 37.27 & 28.92 \\
\hline $\mathrm{CaO}$ & 5.02 & 8.36 & 3.05 & 2.27 \\
\hline $\mathrm{Na}_{2} \mathrm{O}$ & 0.18 & 0 & 1.63 & 0.08 \\
\hline $\mathrm{K}_{2} \mathrm{O}$ & 0.15 & 0 & 0.04 & 0.01 \\
\hline S & 1.90 & - & - & - \\
\hline $\log _{10} C_{S}$ & -5.446 & -5.435 & -5.560 & -5.091 \\
\hline$X_{S \mathrm{Si}}^{\text {sil }} w t \%^{e}$ & 26.60 & 22.91 & 24.69 & 20.79 \\
\hline$X_{S i}^{m e t} w t \%^{f}$ & 28.5 & 28.5 & 27.9 & - \\
\hline
\end{tabular}

All oxide values are wt\%. ${ }^{a}$ Mean of Zolotov et al. (2013) northern volcanic plains and intercrater plains compositions; ${ }^{b}$ Chabot et al. (2014) experimental starting material; cNittler et al. (2018) mean estimated mantle composition; ${ }^{d}$ Average of $\mathrm{H}$-chondrite and $\mathrm{H}+\mathrm{CM}$ chondrite mix (Toplis et al. 2013) and OIM and BD compositions (Lodders 2000). Average Vesta metal composition (wt\%): Fe 76.32, Ni 9.63, Co 0.096, $\mathrm{S} 12.98 ;{ }^{e}$ Mean value is $24.73 \mathrm{wt} \%{ }^{f}{ }^{f}$ At $2 \mathrm{wt} \% \mathrm{~S}$ in metal

structure is calculated using the methodology and material properties of metal and silicate described elsewhere (Helffrich 2017). The choice of $\frac{1}{2} P_{\mathrm{CMB}}$ is motivated by various studies of moderately siderophile element concentrations in the mantle (Tuff et al. 2011; Rubie et al. 2011 ) that find a best fit if magma ocean pressure $P_{\mathrm{BMO}}$ is $2 / 7 \leq P_{\mathrm{BMO}} / P_{\mathrm{CMB}} \leq 2 / 3 ; \frac{1}{2}$ is a useful approximation to the mean pressure.

Because they are cast as exchange reactions, our models are not explicitly dependent on oxygen fugacity $\left(f_{\mathrm{O}_{2}}\right)$, which, on Mercury, is quite low relative to the iron-wüstite buffer (Namur et al. 2016). The major element content, rather, implies an $f_{\mathrm{O}_{2}}$. On the Earth, the variation in equilibrium partitioning conditions for various moderately siderophile elements leads one to invoke a change in the composition of accreting material (or, equivalently, $f_{\mathrm{O}_{2}}$ ) (Wood et al. 2006; Rubie et al. 2011), but we lack the information required to evaluate this for Mercury. For the Earth, there was an evolution to +1 or $+1.5 \log$ units more oxidizing conditions through accretion, but at all times was more oxidizing than Mercury's present conditions (Wood et al. 2006; Namur et al. 2016).

In order to test the model and demonstrate its suitability for other silicate bodies, we recruit Vesta. Its total and core mass are known from the Dawn mission, and the silicate composition is represented by the HED meteorite suite, thought to represent Vesta fragments; Vesta is also believed to have self-differentiated and was not subject to significant mass loss by impact erosion (Russell et al. 2012) (but see Consolmagno et al. (2015) for an alternative view). Various efforts to model Vesta's differentiation using HED meteorites provide Vesta silicate and core compositions (Toplis et al. 2013; Mandler and Elkins-Tanton 2013) whose average is given in Table 3. We use the sulfur partitioning model to calculate the equilibrium sulfur content of Vestan silicate. We modify the solution method slightly for this case and fix the metal's carbon concentration to the low-pressure saturation value in metal, $3.5 \mathrm{wt} \%$ (Tafwidli and Kang 2017). The differentiation pressure is the CMB pressure (Fig. 1) and temperature is midway between the peridotite solidus and liquidus. Figure 1 shows the results. At Vestan differentiation pressures $(<0.1 \mathrm{GPa}), X_{\mathrm{S}}^{\text {sil }}$ is limited to $0.47-0.55$ $\mathrm{wt} \%$ depending on the core's $\mathrm{Si}$ concentration, which is constrained by Si partitioning experiments between metal and silicate (Fischer et al. 2015). The sulfur contents of individual eucrite analyses (Kitts and Lodders 1998) is $0.21 \pm 0.22 \mathrm{wt} \%$ (ranging from 0.03-1.02 wt\%). Hence, metal-silicate equilibration in Vesta may be demonstrated at the $2 \sigma$ level with the model. A further comparison, though requiring further inferences that weaken its verdict, may be made using the estimated S content of the whole HED meteorite suite (Steenstra et al. 2019). They estimate $S$ in HED silicate to be $0.13 \pm 0.04 \mathrm{wt} \%$. The depletion of volatile lithophile elements in HED meteorites appears to be 3-4 times relative to chondrites (Ruzicka et al. 2001). Hence, from these values, 3-4 times $0.13 \mathrm{wt} \%$ meteorite $\mathrm{S}$ yields $0.39-0.52 \mathrm{wt} \% \mathrm{~S}$ in bulk Vesta silicate, which is within our model estimate's range. This validates the model against the composition of a relatively well-known protoplanetary body.

\section{Isotopic model}

The ${ }^{30} \mathrm{Si}$ isotope balance for bulk Mercury (subscript $b$ ) may be written in terms of its partitioning between the core's metal (subscript $c$ ) and the mantle's silicate (subscript $m$ )

$$
\delta^{30} \mathrm{Si}_{b}=f_{c} \delta^{30} \mathrm{Si}_{c}+\left(1-f_{c}\right) \delta^{30} \mathrm{Si}_{m},
$$

where $f_{c}$ is the $\mathrm{Si}$ mass fraction of the core relative to the planet (reckoned as 0.2918 for proto-Mercury core mass fraction of 0.26). To account for the silicate-metal partitioning during core formation, we use temperaturedependent fractionation factors $\Delta^{30} \mathrm{Si}(T)$. Hence,

$$
\delta^{30} \mathrm{Si}_{c}=\Delta^{30} \mathrm{Si}(T)+\delta^{30} \mathrm{Si}_{m} .
$$

The fractionation factor expressions $\Delta^{30} \mathrm{Si}(T)$ are either $\Delta^{30} \mathrm{Si}(T)=-7.45( \pm 0.41) \times 10^{6} / T^{2}$ (Shahar et al. 2011) or a composite value derived from various fractionation factor studies: Shahar et al. (2011), Ziegler et al. (2010), Georg et al. (2007), and Hin et al. (2014). To form the composite fractionation factor, we average using 

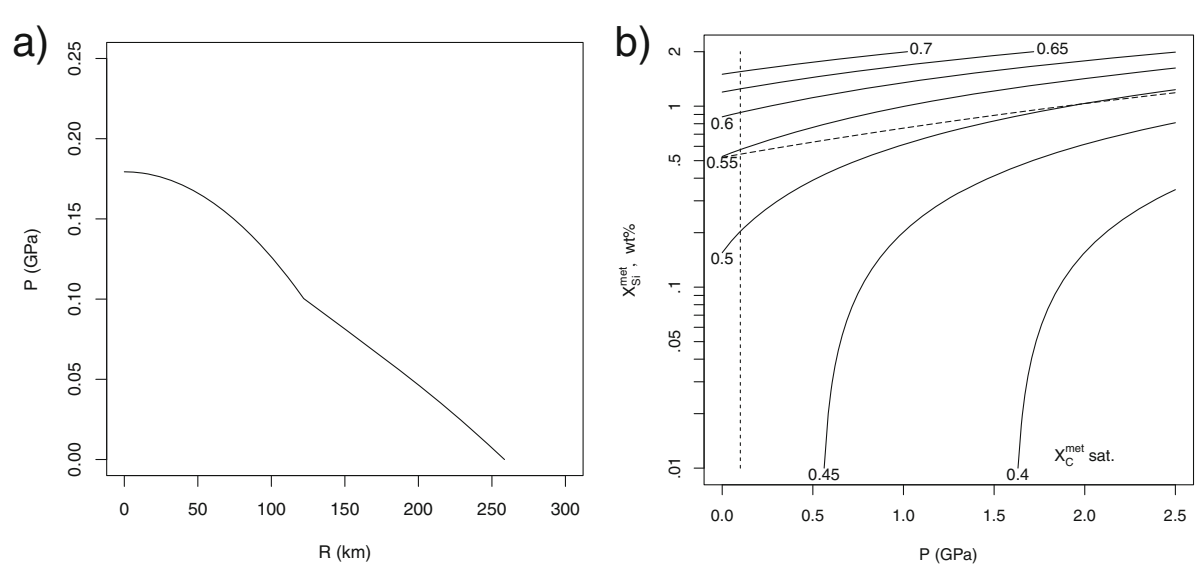

Fig. 1 a Internal pressure within Vesta, using geodetic data from Russell et al. (2012) and methods from Helffrich (2017). Core-mantle boundary (CMB) pressure is evident in knickpoint in $P(R)$ curve. b Sulfur model applied to Vesta, using average estimates of bulk Vesta composition. Contours show wt\% S in Vesta silicate assuming metal-silicate equilibrium at indicated pressure $(P)$ and sulfur content of silicate $X_{S}^{\text {sil }}$. Dashed vertical line is Vestan CMB pressure from $\mathbf{a}$. Sloped horizontal line is $X_{S i}^{m e t}$ calculated from metal-silicate equilibrium at the given pressure. For equilibration pressures at or below the Vestan CMB (lower left), silicate sulfur content is $0.47 \leq X_{S}^{\text {sil }} \leq 0.55 \mathrm{wt} \%$. For measured eucrites, $0.03 \leq X_{S}^{\text {sil }} \leq 1.02 \mathrm{wt} \%$ (Kitts and Lodders 1998)

$1 / \sigma^{2}$ weights with reported uncertainties, where available. Georg et al.'s (2007) calculations yielded two separate fractionation factor values that we average and adopt half of their difference as the uncertainty. The uncertainty estimation procedure for the value derived from Hin et al.'s (2014) experiments is not clearly described, so we took a weighted average of their values at the two experimental temperatures and fit those two values to a $10^{6} / T^{2}$ model to obtain an estimated value and uncertainty. The individual values (and uncertainties) divided by $10^{6}$ are, respectively, $-7.64 \pm 0.47,-7.45 \pm 0.41,-5.65 \pm 0.15$, and $-5.05 \pm 1.58$, which yield a composite fractionation factor of $\Delta^{30} \mathrm{Si}(T)=-6.00( \pm 1.21) \times 10^{6} / T^{2}$.

The mean values for various chondrite classes provide $\delta^{30} \mathrm{Si}_{b}$. Combining (4) and (5), $\delta^{30} \mathrm{Si}$ for the silicate of the proto-Mercury is

$$
\delta^{30} \mathrm{Si}_{m}=\delta^{30} \mathrm{Si}_{b}-f_{c} \times \Delta^{30} \operatorname{Si}(T) .
$$

\section{Results}

The experimentally determined metal-silicate partition coefficient for sulfur (1) may be written as

$$
D_{S}=f\left(P, T, C_{S}, W_{\mathrm{FeO}}^{\mathrm{sil}}, X^{\mathrm{met}}\right),
$$

where $f$ is a function of pressure $(P)$, temperature $(T)$, the sulfur carrying capacity of the silicate $C_{S}(2)$, the $\mathrm{FeO}$ concentration in the silicate, and the metal composition $X^{\text {met }}$. Mercury's silicate composition (Table 3 ) may then be used to find the $P-T$ conditions where metal-silicate equilibrium is achieved if the metal composition is known.
The three silicate compositional estimates are derived in various ways from surface spectroscopic observations (Table 3). The most straightforward is to assume that the surface represents bulk Mercury. Zolotov et al.'s (2013) estimates of the composition of crustal lavas on Mercury provides this compositional choice. It neglects any differentiation that arises from partial melting of the mantlemelt fractions are thought to be $25-40 \%$ (Nittler et al. 2018)-but has the virtue of being purely observationally based. Chabot et al. (2014) attempted to reproduce Mercury's surface composition experimentally by melting mixtures of silicate and metal. We use the experimental starting silicate as a second estimate of the mantle composition. A virtue of this choice is that there is no model underlying it except for being a plausible parental source composition. However, the composition is simplified, lacking alkalis (Table 3). The final estimate is by a formal back-calculation from the surface composition of the mantle's composition assuming that it was formed by batch decompression melting as solid convectively rose along an adiabat (Nittler et al. 2018). For fidelity with the modeling assumptions, we use the model's reported output composition (0.02-0.04 wt\% FeO, Table 3) rather than the one augmented by the addition of $1 \mathrm{wt} \% \mathrm{FeO}$ reported by those authors. There is no significant difference in the results no matter which compositional model is used, so the results shown in Fig. 2 are using Nittler et al.'s (2018) estimate; see Additional file 1: Figure S2 for the results using the other starting compositions. Based on an assumption of an enstatite chondrite origin for Mercury and the content of its surface lavas, Namur et al. (2016) estimated the $f_{\mathrm{O}_{2}}$ of formation conditions 


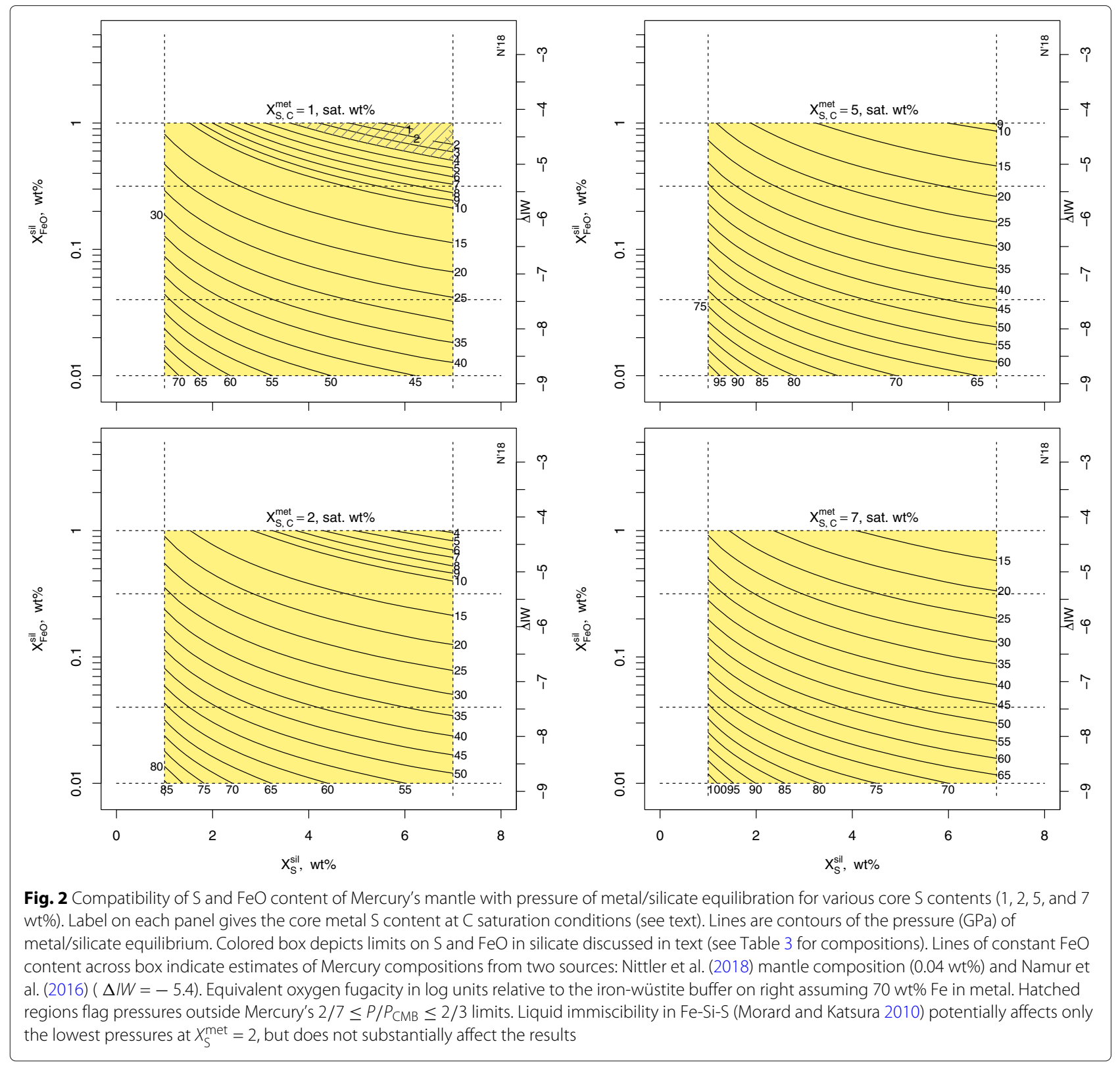

as $-5.4 \log _{10}$ units relative to iron-wüstite, which constrains $\mathrm{FeO}$ to $\sim 0.3 \mathrm{wt} \%$. We use this as an upper bound on the range of possible silicate $\mathrm{FeO}$ content. The same authors also analyzed Mercury surface spectroscopic data to estimate the surface $\mathrm{S}$ content, finding terrane mean ranges from 1.6 to $2.5 \mathrm{wt} \%$. From melt modeling, they reckon the source of the surface lavas contains $2-12 \mathrm{wt} \% \mathrm{~S}$, but favor $7-11 \mathrm{wt} \%$ on the basis of their $f_{\mathrm{O}_{2}}$ estimate and sulfur saturation model. The $\mathrm{FeO}$ estimates provided by the two studies are not mutually compatible; we adopt an inclusive range of $0.01-0.3 \mathrm{wt} \%$ for $\mathrm{FeO}$ (but show values up to $1 \mathrm{wt} \%$ ) and, for $\mathrm{S}$, adopt a narrower $1-7 \mathrm{wt} \%$ range because we do not assume $\mathrm{S}$ saturation in the silicate as Namur et al. (2016) does.
Studies of Mercury's gravity field and spin state provide limits on the sulfur content of its core through their compatibility with the planet's polar moment of inertia and its mantle's moment of inertia. Dumberry and Rivoldini (2015), extending Rivoldini and Van Hoolst's (2013) work, explored a range of $\sim 1-15 \mathrm{wt} \%$ for the sulfur content of the core, but commonly found contents $\sim 5 \mathrm{wt} \% \mathrm{com}$ patible with the geodetic data. Hauck II et al. (2013) also explored compositional constraints on Mercury's core but used only a moment of inertia rotational data which do not provide as tight constraints. We therefore examine compositions with $X_{\mathrm{S}}^{\text {met }}$ of $1,2,5$, and $7 \mathrm{wt} \%$. For each of these sulfur compositions, Fig. 2 shows the feasible pressure and compositional ranges that simultaneously satisfy 
the $\mathrm{S}, \mathrm{Fe}, \mathrm{Si}$, and $\mathrm{O}$ partitioning between core metal and mantle silicate at $\mathrm{C}$ saturation.

The pressure for metal-silicate equilibrium in Mercury depends on the core sulfur content (Fig. 2). At low values ( $1 \mathrm{wt} \%)$, the pressure is $\sim 7-75 \mathrm{GPa}$ and increases to $\sim 11-103 \mathrm{GPa}$ at $7 \mathrm{wt} \%$. For most of the core's sulfur composition range, the equilibrium pressure exceeds the present $\mathrm{CMB}$ pressure, $\sim 6 \mathrm{GPa}$ (Rivoldini et al. 2009; Rivoldini and Van Hoolst 2013), suggesting that the metal-silicate equilibrium took place in a larger planet.

Some insights into how large the earlier planet may have been may be derived from planetary metal proportions $f_{\text {metal }}\left(=M_{\text {core }} / M_{\text {body }}\right)$ and the planetary $\mathrm{Fe} / \mathrm{Mg}$ mass ratio. Figure 3 shows the relations for the rocky planets, Vesta, and for enstatite and carbonaceous chondrites. Mercury is a clear outlier, even compared to metal-rich $\mathrm{CB}$ chondrites that are not thought to be viable Mercury building blocks (Cartier and Wood 2019). However, by adding back silicate with the composition of Mercury's bulk silicate, we see a trend leading back to the cluster that the Solar System's other rocky bodies define. Between 1 and 3 additional $M_{\varnothing}$ of silicate would place it within the solar system's terrestrial grouping.

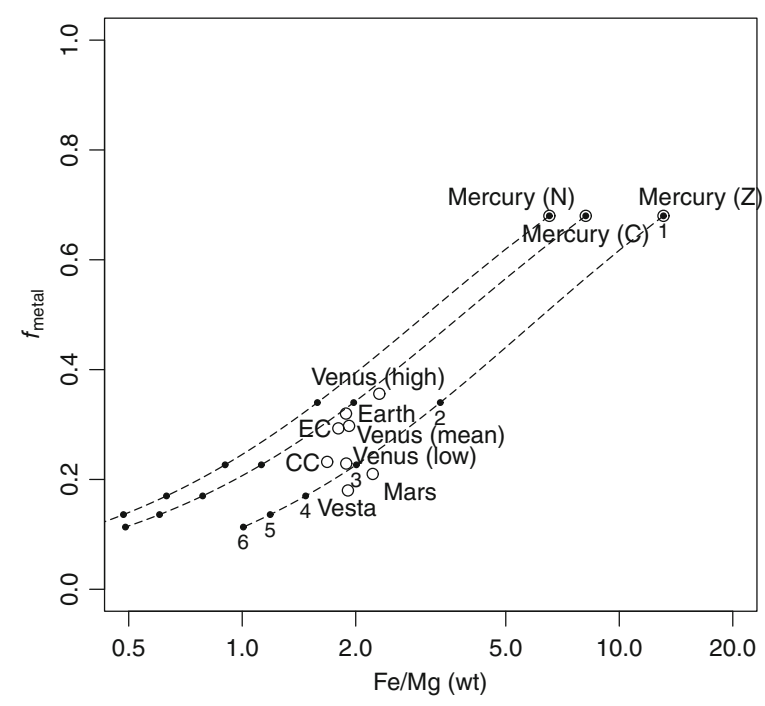

Fig. 3 Metal weight fraction ( $f_{\text {metal }}$ ) versus planetary Fe/Mg mass ratio for various rocky bodies and chondritic meteorite classes (EC, enstatite; CC, carbonaceous). Bulk Mercury estimates from Nittler et al. (2018), Chabot et al. (2014), and Zolotov et al. (2013). Mercury is a singular outlier from the cluster defined by the other objects. Dashed line is trend from silicate added to Mercury with the composition of its bulk silicate (Table 3); points on line show total body mass in units of My. An original mass $2-4 \times M y$ would put it within the rocky body cluster. Data are from Fegley (2014), Dumoulin et al. (2017), McDonough and Sun (1995), Rivoldini et al. (2011), Javoy et al. (2010), and Table 3
To explore the additional silicate added to Mercury needed to permit metal-silicate equilibrium, we adopt an approach used in many simulations of major- and traceelement partitioning between the metal and silicate during planetary accretion (Wade and Wood 2005; Rubie et al. 2011). We assume a planet-wide magma ocean whose base is at $\frac{1}{2} P_{\mathrm{CMB}}$ and calculate the mass of the planet required to achieve the equilibration pressure, which may be viewed as equivalent to a single-stage core formation model or a continuous core formation model for elements whose metal/silicate concentration ratios do not change significantly during accretion (principally the lithophile elements, but also some moderately siderophile elements, e.g., Tuff et al. (2011)).

Figure 4 shows the results. The pressure at the magma ocean's base, $P_{\mathrm{BMO}}=\frac{1}{2} P_{\mathrm{CMB}}$, is the anticipated equilibration pressure whose uncertainty is taken from various accretion scenarios, showing that $2 / 7 \leq P_{\mathrm{BMO}} / P_{\mathrm{CMB}} \leq 2 / 3$ (Tuff et al. 2011; Rubie et al. 2011). Thus the intersection of the $P_{\mathrm{BMO}}$ curve with the minimum equilibration pressure for each core sulfur content yields the range of the minimum added silicate mass required to allow metal-silicate equilibrium. All $X_{\mathrm{S}}$ ranges explored entail added silicate: $0.4-1.5 M_{\varnothing}$ (1 wt\%), 0.8-3.2 $M_{\zeta}(2 \mathrm{wt} \%)$, and > $1.8 M_{\zeta}(5,7 \mathrm{wt} \%)$. Thus, from a bulk chemistry standpoint alone, at least 0.4 $M_{\varnothing}$ was lost from Mercury. An additional constraint is the planetary $\mathrm{Fe} / \mathrm{Mg}$ ratio and its comparison to the ratio in terrestrial solar system bodies and chondritic precursors (Fig. 4). At low core S content (1 wt\%), the Fe/Mg range lies outside the range, rendering it infeasible on compositional grounds. Only at a core sulfur content of $\sim 2 \mathrm{wt} \%$ and higher does metal/silicate sulfur partitioning also satsify $\mathrm{Fe} / \mathrm{Mg}$ constraints. A core sulfur content of $\sim 2$ $\mathrm{wt} \%$ yields planetary $\mathrm{Fe} / \mathrm{Mg}$ and metal ratios in the known range of the other rocky bodies. A minimum of 0.8-3.3 $\times M_{\varnothing}$ added silicate is required to yield a Mercury bulk silicate composition controlled by metalsilicate equilibrium for this core composition. More S-rich cores for Mercury require higher equilibration pressures (Fig. 2) and suggest larger sizes for the protoMercury. Added silicate amounts of $\sim 1-3 M_{\varnothing}$ yield both $\mathrm{Fe} / \mathrm{Mg}$ ratios in the chondritic range and metal mass fractions compatible with the other terrestrial planets.

It is worth highlighting some limitations of our approach. Firstly, we have no direct samples or observations of Mercury's mantle composition, so it is inferred. The surface compositions, from which all Mercury silicate estimates are derived, are obtained from re-emission of energy radiated during solar flares (Nittler et al. 2011), and strictly sample only the top tens of micrometers of Mercury's surface. If the surface were completely mantled by a late veneer, its bulk composition would 


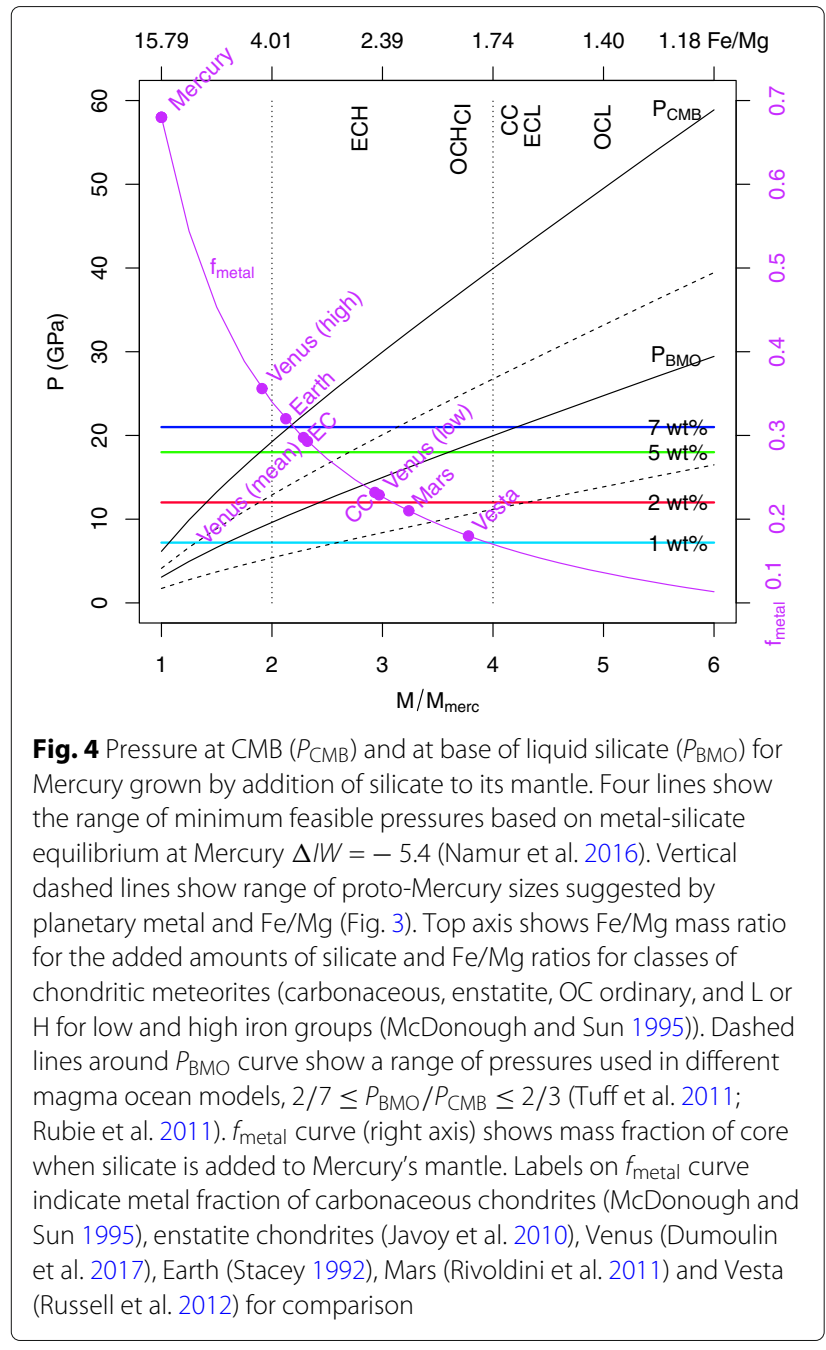

be masked. Mercury imaging shows extensive volcanic formations, however, whose compositions are individually distinct (Zolotov et al. 2013; Namur et al. 2016), making any overall mantling unlikely, but possible still.

Our modeling is essentially driven by the surface silicate composition, from which the core composition is derived consistent with thermodynamic and experimental data and models. If Mercury is chondritic, some key major element ratios obtained by proportionally combining the silicate and core compositions should also be chondritic. In particular, $\mathrm{Fe} / \mathrm{Si}$ and $\mathrm{Mg} / \mathrm{Si}$ should be. With Additional file 1: Figure S3, one can see that the comparison is imperfect but encouraging. Either the silicate estimates are insufficiently rich in $\mathrm{Mg}$ relative to $\mathrm{Si}$ or the modeled core metal $\mathrm{Si}$ content is too high. It is unclear where the problem lies, but, again, the surface composition estimate relies on more model-dependent assumptions than does the sulfur partitioning model.

The sulfur partitioning model we use is experimentally calibrated to only $23 \mathrm{GPa}$, yet we employ it to high pressures; the extrapolation is questionable. However, the constraints it provides are essentially low-pressure ones: for Vesta $(<1 \mathrm{GPa})$ and for the lowest pressures of metalsilicate equilibration (5-25 GPa). Hence, the main results derive from pressures within the model's applicability range.

We rely on geodetic studies that assume that $\mathrm{S}$ is the main constituent of Mercury's core. This is certainly wrong from a chemical perspective, because our models demand knowledge of the core's $\mathrm{Ni}, \mathrm{Si}, \mathrm{O}$, and $\mathrm{C}$ contents too. Whether density profiles for chemically realistic Mercury core compositions would change the compositional constraints the geodetic studies provide is an open question.

\section{Discussion}

From N-body and SPH impact simulations, Benz et al. $(1988,2007)$ reckoned that Mercury's original mass must have been $\sim 2.25 \times M_{\varnothing}$, whereas Asphaug and Reufer (2014) found that impactors between 2.7-5.4×M૪, striking a proto-Venus- or proto-Earth-sized target at glancing incidence $\left(>30^{\circ}\right)$ shed sufficient mass to yield Mercurylike residues. These limits overlap with the chemical equilibration for $X_{\mathrm{S}}^{\text {met }}$ of 2-5 wt\% (Fig. 4). Though chemical equilibrium imposes no useful upper limit to Mercury's original size, similarity to the Solar System's other rocky bodies does. A Mercury constructed from added silicate could have had no more than about three masses added to it before it would exceed the Solar System's rocky body $\mathrm{Fe} / \mathrm{Mg}$ ratios (Fig. 3).

The estimated compositions also place limits on the $\mathrm{Si}$ content of Mercury's core, $X_{\mathrm{Si}}^{\mathrm{met}}$, which is shown in Fig. 5a. The mean $X_{\mathrm{Si}}^{\mathrm{met}}$ depends on the pressure, though Si solubility in metal is not strictly pressure-dependent (Fischer et al. 2015; Hirose et al. 2017) but other metal components are (e.g., O) that affect $\gamma_{S i}$ (Table 2). The variation shown in Fig. 5a shows a further dependence on core sulfur content, justifying, post hoc, the geodetic modeling approach (Rivoldini et al. 2009; Rivoldini and Van Hoolst 2013; Hauck II et al. 2013; Dumberry and Rivoldini 2015). If so much silicate was lost from Mercury, there might be some as yet unidentified meteorite material derived from the debris of its stripped mantle (Gladman and Coffey 2009); Cartier and Wood (2019) note that aubrites would be good candidates for Mercury surface fragments. As an identification aid for Mercuryderived meteorites, stable silicon isotope analyses might be a useful discriminant due to silicon isotope fractionation during core formation (Georg et al. 2007; Fitoussi and Bourdon 2012; Hin et al. 2014). To draw up a silicon isotope budget, we need the core and silicate masses for the planet, and the concentration of silicon in the metal and silicate. We use the silicate composition from Table 3 to obtain the elemental Si content $(24.73 \mathrm{wt} \%)$ and use 


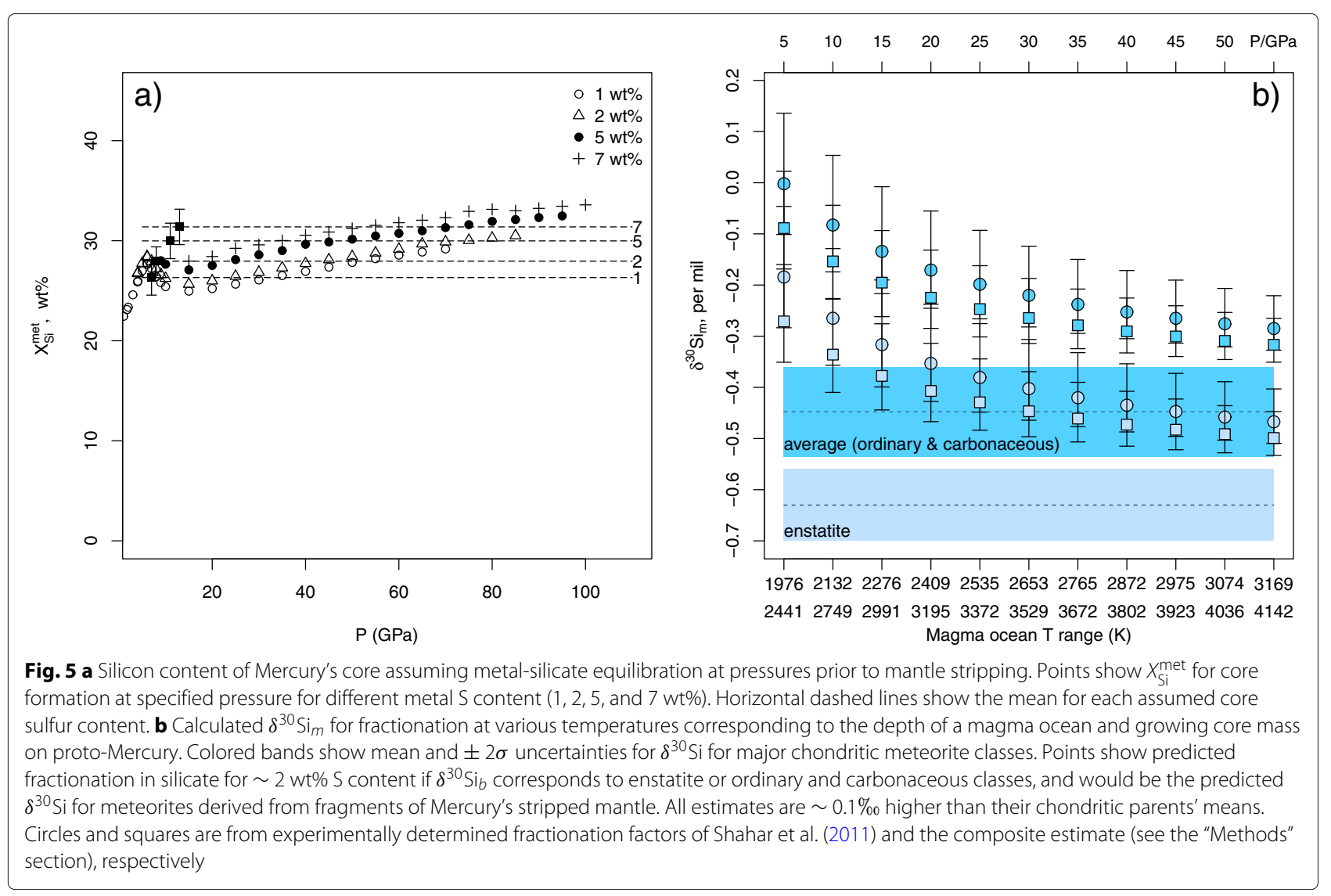

the mean core Si content to calculate the silicate-metal partitioning of ${ }^{30} \mathrm{Si}$ during core formation. Lacking knowledge of the bulk Mercury $\delta^{30} \mathrm{Si}$, we use the mean values for various chondrite classes reported by Armytage et al. (2011): enstatite chondrites $-0.63 \%$ ordinary and carbonaceous chondrites $-0.45 \%$ The results are shown in Fig. 5b. We find that offsets of $+0.10 \%$ or more in $\delta^{30} \mathrm{Si}$ relative to any chondritic parent would be characteristic of meteorites derived from the proto-Mercury body if either Shahar et al.'s (2011) fractionation factor is used or a composite factor derived from all sources. Due to Mercury's similarity to enstatite chondrites (Cartier and Wood 2019), these would be the likely parent material, and at low (15-20 GPa) magma ocean pressures corresponding to $2.5-3 \times M \varnothing$ proto-Mercurys, $\delta^{30} \mathrm{Si}$ offsets would be $\sim+0.20 \%$ (Fig. 5b). The trend with lower pressures also suggests that even if no stripping occurred, Mercury-derived meteorites would have significant $\delta^{30} \mathrm{Si}$ offsets $>+0.3 \%$. Hence, the $\mathrm{S}$ and $\mathrm{FeO}$ content of the silicate, along with the $\delta^{30} \mathrm{Si}$ offset from enstatite chondrites, might prove to be a useful signature of Mercury provenance.

If Mercury was originally a few times its current mass and its mantle was lost through a giant impact (Benz et al. 1988; Benz et al. 2007; Asphaug and Reufer 2014), where did this material go? Benz et al. (1988) concluded that the large impact scenario could only work if the ejected material was not subsequently re-accreted by Mercury. From $N$-body simulations of the ejecta, Benz et al. (2007) concluded that only a small fraction of ejected material would collide with Venus or be removed from Mercury-crossing orbits through secular perturbations. Even if launch speeds of ejecta from Mercury are high enough to place them on Venus- and Earth-crossing orbits, only a few percent of this material collides with the other two planets (Gladman and Coffey 2009). Only if the debris was centimeter-sized and thus affected by Poynting-Robertson drag could material be efficiently removed from this region in a few million years (Benz et al. 2007; Gladman and Coffey 2009). Benz et al. (2007) compute that the size of ejecta material has a peak below $1 \mathrm{~cm}$, making Poynting-Robertson an attractive way to remove material before most of it reaccretes onto Mercury.

Asphaug and Reufer (2014) proposed solving the problem of ejecta re-accretion onto Mercury by making Mercury the impactor rather than the target. If protoMercury formed in the outer, volatile-rich regions of the protoplanetary disc and, additionally, suffered multiple, lower speed collisions with other targets, it could also retain volatile sulfur (Hauck II et al. 2013; Asphaug and Reufer 2014; Cartier and Wood 2019), solving yet another Hermean chemical conundrum. 


\section{Conclusions}

In this study, we used the concept of metal-silicate partitioning in magma ocean conditions to constrain the pressure at which Mercury's silicate and metal could have been in equilibrium. An experimentally derived model of partitioning for sulfur provided the required pressurecomposition relationship. The structure of Vesta and candidate Vestan silicate compositions provided a demonstration of the suitability of the model by showing that it yields, at Vestan equilibration pressures, silicate $S$ content equivalent to Vesta's.

Applying the same model to Mercury, using its observed surface silicate composition and estimates of its core composition from space geodetic studies, we find that equilibration may be achieved if Mercury was originally a larger planet 1.4-2.5 times more massive, and possibly 2-4 times so. Hence Mercury's surface chemistry and geodetic parameters are compatible with silicate mass loss through collision with other objects, or by it having been an impactor itself.

We used the estimated compositions of Mercury's core to calculate the stable silicon isotope fractionation between core metal and mantle silicate. $\delta^{30} \mathrm{Si}$ offsets of $+0.10 \%$ relative to ordinary, enstatite or carbonaceous chondrite precursors would arise, and, if Mercury's original mass was $2.5-3 \times M_{\varnothing}$, the shifts would be $\sim+0.20 \%$. Even if no mantle stripping occurred, the fractionation trend implies offsets in excess of $+0.30 \%$. These offsets could fingerprint meteorite fragments derived from Mercury.

The future mission to the asteroid Psyche (Lord et al. 2017) may yield data to decide whether the body represents the end-point of a silicate stripping process. If there is sufficient mantling silicate for estimating its mantle's composition and if the silicate retains sufficient sulfur, a chemical approach similar to that used here may reveal Psyche's original mass as well.

\section{Supplementary information}

Supplementary information accompanies this paper at https://doi.org/10.1186/s40645-019-0312-z.

Additional file 1: Discussion of $f_{\text {metal }}$ for chondritic meteorites. Figure S1 Carbon saturation as a function of pressure. Figure S2a Compatibility of S and $\mathrm{FeO}$ content of Mercury's mantle with pressure of metal/silicate equilibration for various core $S$ contents (1, 2,5 and 7 wt $\%)$, using Chabot bulk silicate composition. Figure $\mathbf{S} \mathbf{2} \mathrm{b}$ Compatibility of $\mathrm{S}$ and $\mathrm{FeO}$ content of Mercury's mantle with pressure of metal/silicate equilibration for various core $S$ contents (1, 2, 5 and 7 wt\%), using Zolotov bulk silicate composition. Figure S3 Comparison of modeled bulk Mercury Fe, Mg and Si against various chondritic meteorite classes.

\section{Acknowledgements}

Thanks to S. Ida and H. Genda for the discussions about planetary accretion, to the reviewers of earlier versions of this paper for improving the approach, and to the handling editor for spotting and remediating flaws of text and concept. Figures and calculations are made using R (R Core Team 2017).

\section{Authors' contributions}

GH designed the study, performed all calculations, and drafted the paper. RB and AS discussed the methods used and contributed to the submitted version's text. All authors read and approved the final manuscript.

Funding

MEXT Kakenhi grant 15 H05832 partially supported this work.

\section{Availability of data and materials}

All data used are in this paper; there are no additional experimental materials associated with the work.

\section{Competing interests}

The authors have no competing interests regarding the Hermean composition or resource exploitation nor in narratives of Mercury's history.

\section{Author details}

${ }^{1}$ Earth-Life Science Institute, Tokyo Institute of Technology, 2-12-1 Ookayama, Meguro-ku, Tokyo, 152-8550 Japan. ${ }^{2}$ Geophysical Laboratory, Carnegie Institution for Science, 5251 Broad Branch Road NW, Washington, DC, 20015 USA.

Received: 11 December 2018 Accepted: 12 November 2019

Published online: 11 December 2019

\section{References}

Armytage RMG, Georg RB, Savage PS, Williams HM, Halliday AN (2011) Silicon isotopes in meteorites and planetary core formation. Geochim Cosmochim Acta 75:3662-3676

Asphaug E, Reufer A (2014) Mercury and other iron-rich planetary bodies as relics of inefficient accretion. Nat Geosci 7:564-568

Benz W, Slattery WL, Cameron AGW (1988) Collisional stripping of Mercury's mantle. Icarus 74:516-528

Benz W, Anic A, Horner J, Whitby JA (2007) The origin of Mercury. Space Sci Rev 132:189-202

Boujibar A, Andrault D, Bouhifd A, Bolfan-Casanova N, Devidal J-L, Trcera N (2014) Metal-silicate partitioning of sulphur, new experimental and thermodynam ic constraints on planetary accretion. Earth Planet Sci Lett 391:42-54

Cartier C, Wood BJ (2019) The role of reducing conditions in building Mercury. Elements 13:39-45

Chabot NL, Wollack EA, Klima RL, Minitti ME (2014) Experimental constraints on Mercury's core composition. Earth Planet Sci Lett 390:199-208

Consolmagno GJ, Golabek GJ, Turrini D, Jutzi M, Sirono S, Svetsov V, Tsiganis K (2015) Is Vesta an intact and pristine protoplanet? Icarus 254:190-201

Dumberry M, Rivoldini A (2015) Mercury's inner core size and core-crystallization regime. Icarus 248:254-268

Dumoulin C, Tobie G, Verhoeven O, Rosenblatt P, Rambaux N (2017) Tidal constraints on the interior of Venus. JGR-Planets 122:1338-1352

Ebel DS, Stewart ST, Nittler LR, Anderson BJ (2018) The elusive origin of Mercury. In: Solomon SC (ed). Mercury: The View After MESSENGER. Cambridge, Cambridge. pp 497-515

Fegley B (2014) Venus. In: Holland HD, Turekian KT (eds). Treatise on Geochemistry. Elsevier, Amsterdam. pp 127-148

Fiquet G, Auzende A. L, Siebert J, Corgne A, Bureau H, Ozawa H, Garbarino G (2010) Melting of peridotite to 140 Gigapascals. Science 329:1516-1518

Fischer RA, Nakajima Y, Campbell AJ, Frost DJ, Harries D, Langenhorst F, Miyajima N, Pollok K, Rubie DC (2015) High pressure metal-silicate partit ioning of Ni, Co, V, Cr, Si and O. Geochim Cosmochim Acta 167:177-194

Fitoussi C, Bourdon B (2012) Silicon isotope evidence against an enstatite chondrite Earth. Science 335:1477-1480

Frost DJ, Asahara Y, Rubie DC, Miyajima N, Dubrovinsky LS, Holzapfel C, Ohtani E, Miyahara M, Sakai T (2010) Partitioning of oxygen between the Earth's mantle and core. J Geophys Res 115:10-10292009006302

Georg RB, Halliday AN, Schauble EA, Reynolds BC (2007) Silicon in the Earth's core. Nature 447:1102-1106

Gladman B, Coffey J (2009) Mercurian impact ejecta: Meteorites and mantle. Meteor Planet Sci 44:285-291

Hauck II SA, Margot J-L, Solomon SC, Phillips RJ, Johnson CL, Lemoine FG, Mazarico E, McCoy TJ, Padovan S, Peale SJ, Perry ME, Smith DE, Zuber MT (2013) The curious case of Mercury's internal structure. JGR-Planets 118:1204-1220 
Helffrich G (2017) A finite strain approach to thermal expansivity's pressure dependence. Am Mineral 102:1690-1695

Hin RC, Fitoussi C, Schmidt MW, Bourdon B (2014) Experimental determination of the Si isotope fractionation factor between liquid metal and liquid silicate. Earth Planet Sci Lett 387:55-66

Hirose K, Morard G, Sinmyo R, Umemoto K, Hernlund J, Helffrich G, Labrosse S (2017) Crystallization of silicon dioxide and compositional evolution of the Earth's core. Nature 543:99-102

Javoy M, Kaminski E, Guyot F, Andrault D, Sanloup C, Moreira M, Labrosse S, Jambon A, Agrinier P, Davaille A, Jaupart C (2010) The chemical composition of the Earth: Enstatite chondrite models. Earth Planet Sci Lett 293:259-268

Kaaden KEV, McCubbin FM (2016) The origin of boninites on Mercury: an experimental study of the northern volcanic plains lavas. Geochim Cosmochim Acta 173:246-263

Kaula WM (1979) Thermal evolution of Earth and Moon growing by planetesimal impacts. J Geophys Res 84:999-1008

Kitts K, Lodders K (1998) Survey and evaluation of eucrite bulk compositions. Met Planet Sci 33:197-213

Li J, Agee CB (1996) Geochemistry of mantle-core differentiation at high pressure. Nature 381:686-689

Lodders K (2000) An oxygen isotope mixing model for the accretion and composition of rocky planets. Space Sci Rev 92:341-354

Lord P, Tilley S, Oh DY, Goebel D, Polanskey C, Snyder S, Carr G, Collins SM, Lantoine G, Landau D, Elkins-Tanton L (2017) Psyche: journey to a metal world. In: 2017 IEEE Aerospace Conference Proceedings. Big Sky, MT. p 11

Ma Z (2001) Thermodynamic description for concentrated metallic solutions using interaction parameters. Met Mater Trans B 32:87-103

Mandler B, Elkins-Tanton $L$ (2013) The origin of eucrites, diogenites, and olivine diogenites: magma ocean crystallization and shallow magma chamber processes on Vesta 48:2333-2349. https://doi.org/10.1111/maps.12135

McDonough WF, Sun S-s (1995) The composition of the Earth. Chem Geol 120:223-253

Morard G, Katsura T (2010) Pressure-temperature cartography of Fe-S-Si immiscibility. Geochim Cosmochim Acta 74:36-59

Namur O, Chalier B, Holtz F, Cartier C, McCammon C (2016) Sulfur solubility in reduced mafic silicate melts: Implications for the speciation and distribution of sulfur on Mercury. Earth Planet Sci Lett 448:102-114

Nittler LR, Starr RD, Weider SZ, McCoy TJ, Boynton WV, Ebel DS, Ernst CM, Evans LG, Goldsten JO, Hamara DK, Lawrence DJ, McNutt RL, Schlemm CE, Solomon SC, Sprague AL (2011) The major-element composition of Mercury's surface from MESSENGER X-ray spectrometry. Science 333:1847-1850

Nittler LR, Chabot NL, Grove TL, Peplowski PN, Nittler LR, Anderson BJ (2018) The chemical composition of Mercury. In: Solomon SC (ed). Mercury: The View After MESSENGER. Cambridge, Cambridge. pp 30-51

Peplowski PN, Lawrence DJ, Evans LG, Klima RL, Blewett DT, Goldsten JO, Murchie SL, McCoy TJ, Nittler LR, Solomon SC, Starr RD, Weider SZ (2015) Constraints on the abundance of carbon in near-surface materials on Mercury: results from the MESSENGER gamma-ray spectrometer. Planet Space Sci 108:98-107

R Core Team (2017) R: a language and environment for statistical computing. $R$ Foundation for Statistical Computing (https://www.R-project.org/), Vienna

Rivoldini A, Van Hoolst T (2013) The interior structure of Mercury constrained by the low-degree gravity field and the rotation of Mercury. Earth Planet Sci Lett 377-378:62-72

Rivoldini A, Van Hoolst T, Verhoeven O (2009) The interior structure of Mercury and its core sulfur content. Icarus 201:12-30

Rivoldini A, Van Hoolst T, Verhoeven O, Mocquet A, Dehant V (2011) Geodesy constraints on the interior structure and composition of Mars. Icarus 213:451-472

Rubie D. C, Frost D. J, Mann U, Asahara Y, Nimmo F, Tsuno K, Kegler P, Holzheid A, Palme P (2011) Heterogeneous accretion, composition and core-mantle differentiation of the Earth. Earth Planet Sci Lett 301:31-42

Rubie DC, Jacobson SA, Morbidelli A, O'Brien DP, Young ED, de Vries J, Nimmo F, Palme H, Frost DJ (2015) Accretion and differentiation of the terrestrial planets with implications for the compositions of early-formed Solar System bodies and accretion of water. Icarus 248:89-108

Russell CT, Raymond CA, Coradini A, McSween HY, Zuber MT, Nathues A, Sanctis MCD, Jaumann R, Konopliv AS, Preusker F, Asmar SW, Park RS, Gaskell R, Keller HU, Mottola S, Roatsch T, Scully JEC, Smith DE, Tricarico P,
Toplis MJ, Christensen UR, Feldman WC, Lawrence DJ, McCoy TJ, Prettyman TH, Reedy RC, Sykes ME, Titus TN (2012) Dawn at Vesta: testing the protoplanetary paradigm. Science 336:684-686

Ruzicka A, Snyder GA, Taylor LA (2001) Comparative geochemistry of basalts from the Moon, Earth, HED asteroid, and Mars: implications for the origin of the Moon. Geochim Cosmochim Acta 65:979-997

Shahar A, Hillgren VJ, Young ED, Fei Y, Macris CA, Deng L (2011) High-temperature $\mathrm{Si}$ isotope fractionation between iron metal and silicate. Geochim Cosmochim Acta 75:7688-2697

Stacey FD (1992) Physics of the Earth. Brookfield Press, Brisbane

Steenstra E. S, Dankers A, Berndt J, Klemme S, Matveev S, van Westrenen W (2019) Significant depletion of volatile elements in the mantle of asteroid Vesta due to core formation. Icarus 317:669-681

Tafwidli F, Kang Y-B (2017) Thermodynamic modeling of Fe-C-S ternary system. ISIJ Int 57:782-790

Toplis M, Mizzon H, Monnereau M, Forni O, Mcsween HY, Mittlefehldt DW, Mccoy TJ, Prettyman TH, Sanctis MCD, Raymond CA, Russell CT (2013) Chondritic models of 4 Vesta: implications for geochemical and geophysical properties. Met Planet Sci 48:2300-2315

Tuff J, Wood BJ, Wade J (2011) The effect of Si on metal-silicate partitioning of siderophile elements and implications for the conditions of core formation. Geochim Cosmochim Acta 75:673-690

Wade J, Wood BJ (2005) Core formation and the oxidation state of the Earth. Earth Planet Sci Lett 236:78-95

Wade J, Wood BJ, Tuff J (2012) Metal-silicate partitioning of Mo and W at high pressures and temperatures: evidence for late accretion of sulphur to the Earth. Geochim Cosmochim Acta 85:58-74

Weider SZ, Nittler LR, Starr RD, McCoy TJ, Solomon SC (2014) Variations in the abundance of iron on Mercury's surface from MESSENGER X-Ray Spectrometer observations. Icarus 235:170-186

Wood BJ (1993) Carbon in the core. Earth Planet Sci Lett 117:593-607

Wood BJ, Walter MJ, Wade J (2006) Accretion of the Earth and segregation of its core. Nature 441:825-833

Ziegler K, Young ED, Schauble EA, Wasson JT (2010) Metal-silicate silicon isotope fractionation in enstatite meteorites and constraints on Earth's core formation. Earth Planet Sci Lett 295:487-496

Zolotov MY, Sprague AL, II SAH, Nittler LR, Solomon SC, Weider SZ (2013) The redox state, FeO content, and origin of sulfur-rich magmas on Mercury. J Geophys Res 118:138-146

\section{Publisher's Note}

Springer Nature remains neutral with regard to jurisdictional claims in published maps and institutional affiliations.

\section{Submit your manuscript to a SpringerOpen ${ }^{\circ}$ journal and benefit from:}

- Convenient online submission

- Rigorous peer review

- Open access: articles freely available online

- High visibility within the field

- Retaining the copyright to your article 